\title{
RECOMBINANT HUMAN BONE MORPHOGENETIC PROTEIN-2 VERSUS AUTOGENOUS BONE GRAFT IN THE RECONSTRUCTION OF MAXILLARY ANTERIOR ALVEOLAR RIDGE DEFECTS
}

\author{
Lamia A. Kader* and Nader N. Elbokle**
}

\begin{abstract}
The purpose of this study was to evaluate the effect of recombinant human bone morphogenetic protein-2 (rhBMP-2) delivered in an absorbable collagen sponge (ACS) carrier on reconstructing the alveolar ridge defect and obtain newly formed bone as an alternative to autogenous bone grafting thus eliminating the dilemma and morbidity related to donor site.

A clinical investigation was carried out on sixteen patients at outpatient clinic of the Oral Surgery Department, Faculty of Oral and Dental Medicine, Cairo University, presented with alveolar ridge defects in the anterior maxilla. Thorough pre-operative assessment of the patients was carried out including history taking, physical examination and radiographic examination. The pre-operative volume, height, width and density of the defective alveolar ridge were measured on Computed Tomographic Cone Beam scan (CBCT).
\end{abstract}

The patients were divided into 2 groups; Group (I) comprised 8 patients who received (rhBMP-2) delivered in an absorbable collagen sponge (ACS), Group (II) comprised 8 patients who received autogenous chin graft.

The follow-up period was 6 months in the form of clinical evaluation and radiographic evaluation by CBCT scans to measure the amount of bone fill and bone density.

At the end of the follow-up period no signs of infection or evidence of bone resorption were found. The radiographs showed newly formed bone and increase in alveolar bone dimensions in all cases.

There was significant increase of bone width, height volume and density six months postoperatively in both group I (rhBMP-2) and Group II (Autogenous Bone) ( $\mathrm{p}<0.001)$. However, there was no significant difference between Group I (rhBMP-2) and Group II (Autogenous Bone) postoperatively as regards bone width, height volume and density respectively $(p>0.01)$.

rhBMP-2/ACS is an alternative source to substitute the autogenous bone graft to obtain newly formed bone and eliminate the dilemma and morbidity related to donor site.

* BDS., MSc., Oral and Maxillofacial Surgery, Faculty of Oral and Dental Medicine, Cairo University, Egypt.

** BDS, MSc, PhD, Assistant Professor of Oral and Maxillofacial Surgery, Department of Oral and Maxillofacial Surgery, Faculty of Oral and Dental Medicine, Cairo University, Egypt. 


\section{INTRODUCTION}

Alveolar ridge bony defects are very common and cause a significant problem in dental treatment and rehabilitation. They can be the result of congenital mal-development, trauma, periodontal disease or surgical ablation, as in the case of tumor surgery ${ }^{[1,2]}$. Tooth extraction is one of the most common dental procedures; the alveolar defect that results as a consequence of tooth removal will only become partially restored. Concurrent with bone growth into the socket, there is also a welldocumented resorption of the alveolar ridges. ${ }^{[3]}$

Although post-extraction socket with intact bone walls are capable of achieving bone regeneration by themselves ${ }^{[4,5]}$, the bone does not regenerate to the level of the horizontal bone crest level of the neighboring teeth; i.e., $100 \%$ socket filling never occurs $^{[6]}$. Resorption after tooth-loss has been shown to follow a predictable pattern; the labial aspect of the alveolar crest is the principal site of resorption, which first reduces in width and later in height ${ }^{[1,2]}$. In the anterior maxilla, bone resorption following tooth loss occurs early (50\% during the first 12 months) mainly in the horizontal direction, with most of the bone loss on the buccal aspect. ${ }^{[7]}$

Araújo \& Lindhe $e^{[8]}$ claimed that marked dimensional alterations with notable osteoclastic activity occurred during the first eight weeks after tooth extraction, resulting in resorption of the Crestal region of both the buccal and lingual bone walls. Moreover, the resorption of the buccal and lingual walls of the extraction site occurred in two overlapping phases. In the first phase, the woven bone was resorbed and replaced with bone tissue. Because the buccal bone wall crest is exclusively composed of woven bone, this remodeling resulted in substantial vertical reduction of the buccal crest. The second phase showed that the resorption occurs from the external area of both bone walls, resulting in a horizontal resorption that can induce additional vertical reduction of the buccal bone.
The magnitude of bone loss is estimated to be $40-60 \%$ during the first 3 years following tooth loss and the decrease to a $0.25-0.5 \%$ annual loss rate $^{[9,10]}$. The bone resorption activity in the residual ridge continues throughout life at a slower rate ${ }^{[1]}$, resulting in the removal of large amounts of jaw structure. The loss of thickness is greater than the loss of alveolar ridge height after dental extraction, and both have been described as being more pronounced in the buccal aspect than in the palatal aspect of the jaws. ${ }^{[3,12,13]}$

The cause for resorption of alveolar bone after tooth-loss has been assumed to be due to disuse atrophy, decreased blood supply, localized inflammation or unfavorable prosthesis pressure $^{[10,14]}$. The defect resulting from tooth loss may be complicated by previous bone loss due to periodontal disease, endodontic lesion or trauma. The defect becomes more compromised when the alveolus has lost walls or height. ${ }^{[15]}$

This resorption process results in a narrower and shorter ridge and the effect of this resorptive pattern is the relocation of the ridge to more palatal/ lingual position ${ }^{[3,8,12]}$. The dislocated ridge makes it more difficult to place the implant in an optimal restoration position without a buccal dehiscence occurring in the implant. ${ }^{[15]}$

This alveolar bone resorption especially in anterior area may cause significant esthetic problems in prosthetic and restorative dentistry as well as surgical problems by making the placement of implants difficult or even impossible unless the volume of bone is increased before implantation. ${ }^{[16]}$

Therefore, ridge augmentation is required to maintain optimal prosthetic replacement of the lost tissue by stimulating bone healing and filling bone defects.

Alveolar ridge reconstruction can be achieved by several surgical techniques and graft materials, for which many studies have been constructed. For many years, the autogenous bone graft has been 
considered the gold standard source of bone for augmentation. by which all techniques of osseous reconstruction of the maxillofacial skeleton must be judged. Fred Albee $e^{[17]}$, first described autologous bone grafting in 1915, using part of the tibia for spinal fusion. Autogenous bone graft contains osteoblasts, endostealosteoprogenitor cells capable of synthesizing new bone, and a structural matrix that acts as a scaffold, making it the gold standard for bone grafting. However, the supply is limited and the donor-site morbidity of autograft can be as high as 25 percent. ${ }^{[18]}$

Autogenous cancellous bone grafts produce the most successful and predictable results. It has been shown that bone grafts taken from the jaws resorb more slowly than other grafts. ${ }^{[19,20,21]}$ This might be due to the origin of jaw bones, which is membranous while other long bones mainly are endochondral ${ }^{[22]}$. Free bone grafts act mostly as scaffolds and are thus more osteoconductive than osteoinductive even though osteogenic activity may have remained in the spongious part of the graft autogenous grafts is the need for a second surgical site and the A point may be reached in reconstruction where the donor site morbidity may exceed the discomfort of the presenting complaint, such potential discomfort is a serious reason for patients to avoid presenting themselves for reconstructive procedures. ${ }^{[23]}$

Nowadays, the researches are directed more towards alternative source to substitute the autogenous grafting. Among these researches; is the use of tissue engineering technology to find substitute for autogenous bone grafts. ${ }^{[24]}$

The initial indication for the existence of Bone Morphogenic Proteins (BMPs) was reported in 1917 with the observation that bone growth was evident in surgically implanted fascia to bridge gaps within the bladder ${ }^{[25]}$. Later, in 1931, Huggins ${ }^{[26]}$ noted that demineralized bone and transitional urinary epithelium possessed osteoinductive capabilities for connective tissue ectopic bone formation. In the 1934, Levander ${ }^{[27,28]}$ noted that crude alcohol extracts of bone induced new bone formation when injected into muscle tissue. In 1961 Sharrard\&Collins ${ }^{[29]}$ reported the use of ethylenediamine-tetraacetic acid-decalcified allograf bone for spinal fusion in children. This idea was studies by Ray \& Holloway ${ }^{[30]}$.

In 1965, Urist ${ }^{[31,32]}$ performed a failed experiment in which he was studying demineralized rabbit and rat bone he hydrochloric acid $(\mathrm{HCl})$ or calcium chloride $(\mathrm{CaCl} 2)$ to use them as a bone allograft. The samples were implanted at subcutaneous sites in rodents, together with non-chemically treated controls. Surprisingly, the samples gave ectopic bone formation. This excellent discovery was published in Science, titled 'Bone formation by autoinduction'. Some years later, he described the protein fractions responsible for this effect and named them "bone morphogenetic proteins". It wasn't until the early 1980s that Sampath\&Reddi ${ }^{[33]}$ clearly demonstrated, using an assay based on the activity of calcium and alkaline phosphatase, that the protein and not its matrix was responsible for ectopic bone formation.

During the decades of $80 \mathrm{~s}$ and $90 \mathrm{~s}$ the BMP genes were cloned and the recombinant proteins were shown to be biologically potent ${ }^{[34]}$. Much work followed with the use of recombinant BMPs (rhBMPs) for clinical applications such as spinal fusion, fracture healing and dental tissue engineering ${ }^{[35,36]}$. Human BMPs are now produced in larger amounts by recombinant technology.

Recently, there have been several studies that have shown that alveolar ridge defects can be reliably repaired with recombinant human bone morphogenetic protein (rhBMP-2).

Therefore, the purpose of this study was to reconstruct the alveolar ridge defect using (rhBMP-2) delivered in an absorbable collagen sponge (ACS) carrier and obtain newly formed bone, compare it with the gold standard autogenous bone graft and eliminate the dilemma and morbidity related to donor site. 


\section{PATIENTS AND METHODS}

A total of Sixteen patients with anterior alveolar ridge defects were selected randomly from the outpatient clinic of the Oral Surgery Department, Faculty of Oral and Dental Medicine, Cairo University.The patients were selected according to the following criteria:

Inclusion criteria: Patient has been edentulous for at least 4 months with an alveolar ridge defect affecting the anterior maxilla. Horizontal ridge width $\leq 4 \mathrm{~mm}$ at the crestal level in the anterior maxilla assessed clinically and/or using CBCT. Patient is a candidate for dental implants in the affected anterior maxillary alveolar ridge area. Patient has a prosthodontic treatment plan in place. Patient is 21-75 years of age. If patient is a female of childbearing potential, she should have a negative urine pregnancy test and is not lactating. Patient should be able to comply with all study-related procedures, including exercising good oral hygiene.

Exclusion criteria: If Patient has an active infection at the planned augmentation site, patient has active periodontal disease of Grade III or higher, patient has had a dental extraction procedure at the planned augmentation site within the last 4 months, patient is smoker, alcohol or drug dependent. Patient has any condition that would place the study at undue risk or interfere with the results of the study.

A thorough preoperative assessment of all patients was carried out including history taking, physical examination and Cone beam CT examination The gathered information concerning history taking and physical examination was recorded into diagnostic sheets.

As mentioned in inclusion/exclusion criteria all patients were free from any systemic condition that might contraindicate operating under local anesthesia or even affect the bone grafting process or cause infection and grafting resorption.

\section{Radiographic Examination:}

\section{Cone Beam Computed Tomography Scan (CBCT Scan)}

Preoperative sectional Cone beam C.T scan of the anterior maxilla was made for each patient, using SoredexCranex 3D machine*. The field of view (FOV) is $6 \times 8 \mathrm{~cm}$.

The Cone beam C.T was used for volumetric assessmentof the defective alveolar ridge and to measure the amount of bone formed in the grafted area at the end of follow-up period.

The defective alveolar ridge was traced on each sagittal cut of $0.5 \mathrm{~mm}$ thickness, following the estimated outline of the labial and palatal cortices using Osirix (V.5.9) software. One measurement of alveolar bone height, three measurements of bone width at $25 \%, 50 \%$ and $75 \%$ of the ridge length and surface area were taken on each cut, then mean values of height and width were calculated. These measurements were recorded as "base line values" and was used to calculate the volume of the defective alveolar ridge.

All patients were informed about the nature of the performed procedures. The patient were asked to read and sign an informed consent document which provides the patient with written information describing all aspects of the clinical trial and possible complications that might occur.

\section{Titanium mesh pre-bending}

In order to ensure accurate adaptation of the titanium mesh pre-bending was performed on a printed stereolithographic 3D model of the defect site. This 3D model was obtained by means of 3D reconstruction of CBCT DICOM files using the software MIMICS ${ }^{*}$ version 16.0.

\footnotetext{
* Soredex Orion Corporation, Helsinki, Finland
} 
DICOM files where imported into MIMICS $®$ software, where soft tissue was eliminated by soft tissue the holding and a 3D model was created. This 3D model file was then processed by CubeX $^{* *}$ software Version 1.8 and printed into a 3D model using CubeX duo** printer.

The printed 3D model was used for pre-bending and adaptation of the titanium mesh. Finally the titanium mesh was sterilized.

\section{Operative Procedures}

The patients were divided into 2 groups; Group (I) received (rhBMP-2) delivered in an absorbable collagen sponge (ACS), Group (II) received autologous chingraft.

The patients of both groups were instructed to rinse their mouths with Chlorhexidine mouth wash ${ }^{* * *}$ for 2 minutes just before surgery. Pre-surgical medications were not provided. All procedures were performed under sterile conditions.

To create the recipient site in both groups, a crestal incision (at the top of the edentulous alveolar crest) and 2 vertical releasing incisions were performed; subsequently, a full-thickness flap was raised. Curettage and removal of any granulation was performed. The buccal aspect of alveolar ridge was scored using diamond round bur $(3 \mathrm{~mm}$ diameter). The pre-bent titanium mesh was tried in place and had a perfect fit. Figures $(1,2)$

In group (I) (rhBMP-2), white lyophilized powder was mixed with $2 \mathrm{ml}$ normal saline loaded in small plastic syringe (specialized for insulin injections and $1 \mathrm{ml}$ graduated as 100 unit) to make solution of rhBMP-2 with a concentration of $1 \mathrm{mg} /$ $\mathrm{ml}$. Then 25 units was drawn by small plastic syringe and applied drop by drop to the absorbable collagen sponge carrier so that the collagen sponge become completely soaked with the rhBMP-2. Figures $(3,4)$

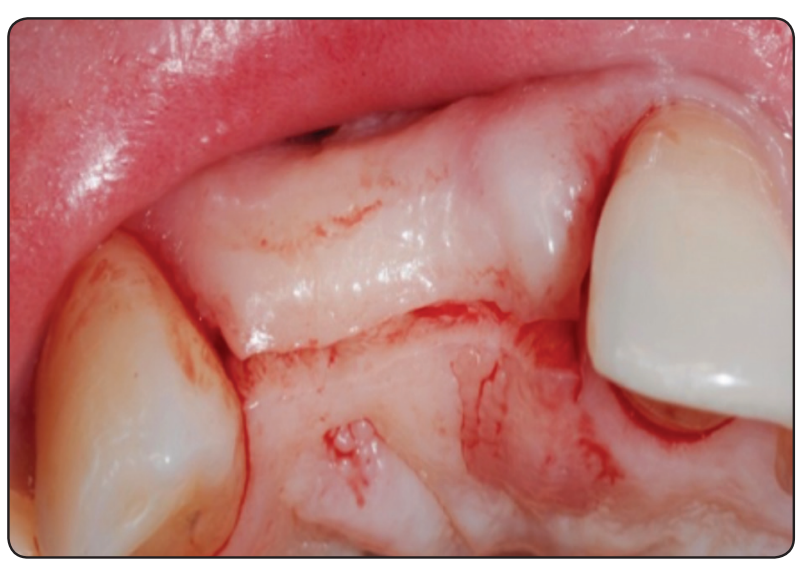

Fig. (1) Showing the incision from palatal view.

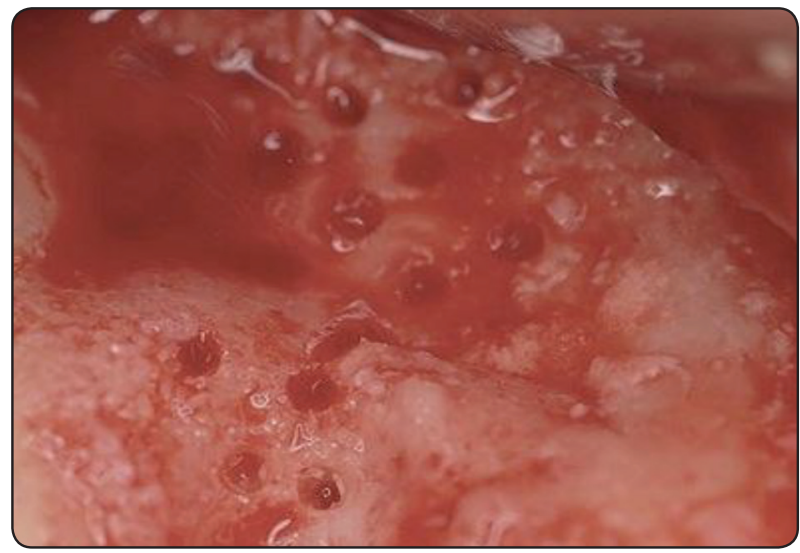

Fig. (2) Showing the buccal aspect of the alveolar ridge after scoring.

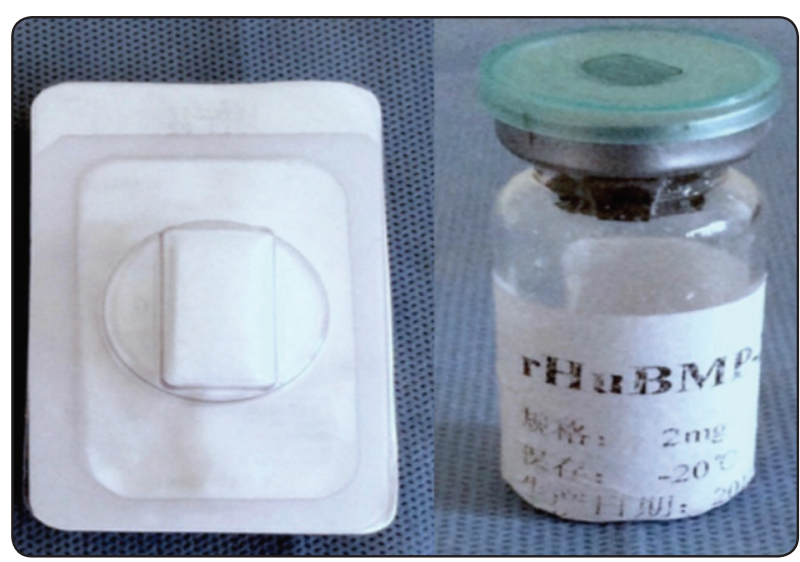

Fig. (3) Showing Collagen Sponge (left), rhBMP-2 (right)

* Materialise N.V., Leuven, Belgium

** 3D Systems Inc., Rock Hill, USA.

***AntiseptolKahira pharm \& chemind co. 


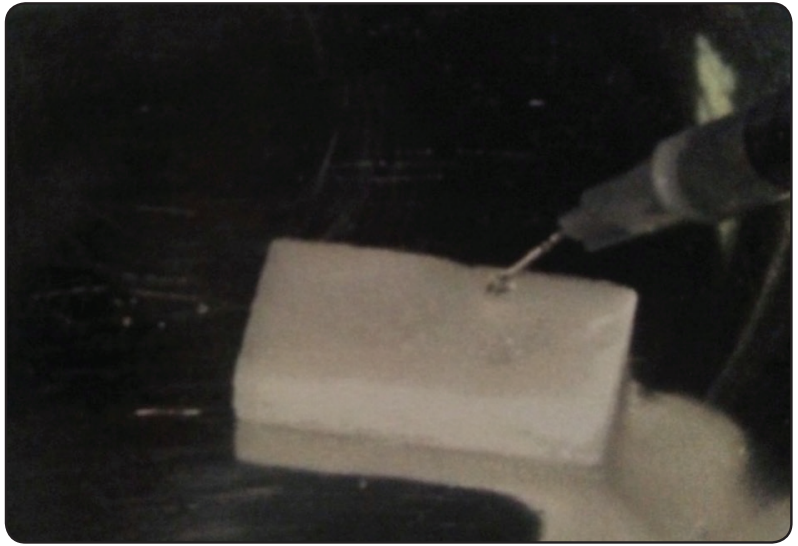

Fig. (4) Showing the rhBMP-2 mixture applied drop by drop to the absorbable collagen sponge.

The number of collagen sponges used differs according to the size of the alveolar ridge defect. (average 2 collagen sponges). The rhBMP- 2 must be allowed to bind to the sponge for 15 minutes to prevent the rhBMP-2 liquid from being washed away by body fluids.

The defect was completely filled with 2-3 sponges according to the size of the alveolar ridge defect. The pre-bent micro-system titanium mesh* $0.2 \mathrm{~mm}$ thick was placed to provide space for bone augmentation, and secured using $1.5 \mathrm{~mm}$ selftapping titanium micro screws*.

In group (II) autogenous bone graft from mandibular symphysis was used. The bone graft was harvested, using a trephine bur $\# 5^{*}$, in the form of small cylindrical blocks, and then particulated using a bone miller. The particulate autogenous bone was applied alone. Figure (5)

In both groups the pre-bend titanium mesh was fixed in position with two or more titanium microscrews* in the buccal and palatal portion of the native bone to maintain and protect the graft in situ.

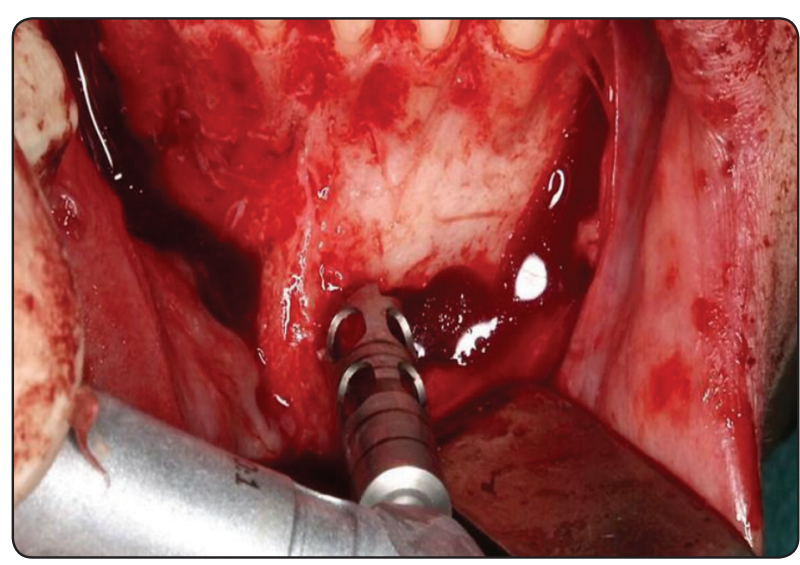

Fig.(5) Autogenous chin bone harvesting using trephine bur.

\section{Postoperative Care}

The postoperative care was the same for all patients of both groups.

Postoperative instructions were given to each patient including; ice packs for 20 minutes every 60 minutes for 24 hours, strict oral hygiene measures in the form of regular irrigation of the intraoral wound site several times per day and regular use of soft toothbrush.

The following postoperative regimen was prescribed: Prophylactic antibiotic; Augmentin** $625 \mathrm{mg}$ tab every 8 hours for 5 days. Also, antiinflammatory analgesic drug; Cataflam ${ }^{* * *} 50 \mathrm{mg}$ tab every 6 hours. And, mouth wash; Chlorhexidine ${ }^{* * * *}$ mouthwash 3-4 times per day for 21 days.

\section{Postoperative Follow-up}

\section{Clinical follow-up:}

Postoperative follow-up was carried out every week during the first month, and then every month for 6 months.

\footnotetext{
* Medicon Company, Germany.

** GlaxoSmithKline

*** Novartis Pharma

**** (Antiseptol): kahira pharm \& chemind co.
} 
The following clinical parameters were evaluated: Examination of the wound, suture breakdown or dehiscence. Checking for any postoperative complication such as: pain, swelling, bleeding, hematoma, infection, bone graft exposure or signs of ectopic bone formation.

Six months after surgery, re-exposure of the augmented sites were performed where the titanium mesh and the stabilizing screws were removed and the bone site prepared for implant placement depending on amount and quality of bone formed.

Radiographic follow-up examination was performed 6 months postoperatively by CBCT scan with the same parameters as the preoperative one. CBCT scan was used to assess volume and density of bone formed.

Volumetric assessment of the newly formed bone in the grafted area was performed 6 months post-operatively.

The efficacy of rhBMP-2/ACS was assessed using $\mathrm{CBCT}$ by the following parameters;

The defective alveolar ridge was traced on each sagittal cut following the estimated outline of the labial and palatal cortices using Osirix (V.5.9) software. Alveolar bone height "one measurement", bone width "three measurements" at 25\%,50\% and $75 \%$ of the ridge length and surface area were taken on each cut, then mean values of height and width were calculated.

These measurements were recorded as "base line values". Then the volume of the defective alveolar ridge was calculated.

These measurements were taken from CBCT scans exposed preoperative and at 6 months postoperative. (Figures 5, 6) [Bone height 6 months (-) Base line values] and [Bone width 6 months (-) Base line values] were calculated, then volume of the newly formed bone was calculated.

To assure standardized image generation during obtaining CBCT scans, patients were provided with custom made scanning stents. Also, all image data sets were reoriented using the software. From each data set, four $0.5 \mathrm{~mm}$ cross sections were generated perpendicular to the occlusal plane. The same regions were represented for baseline and 6 months post-operative. Images contained a ruler, which allowed the setting of the linear scale of each image, and also three reference lines to standardize the localization of the measurements at 2, 6 and 10 $\mathrm{mm}$ above the alveolar crest (immediate sub-, midand apical crestal levels respectively). Figures $(6,7)$

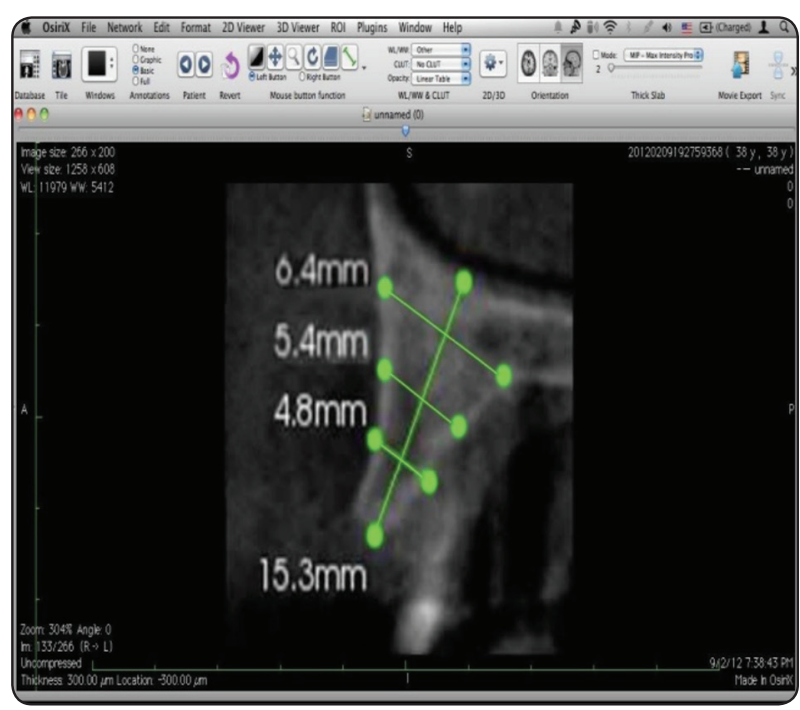

Fig.(6) Alveolar bone height and bone width measurements pre-operative.

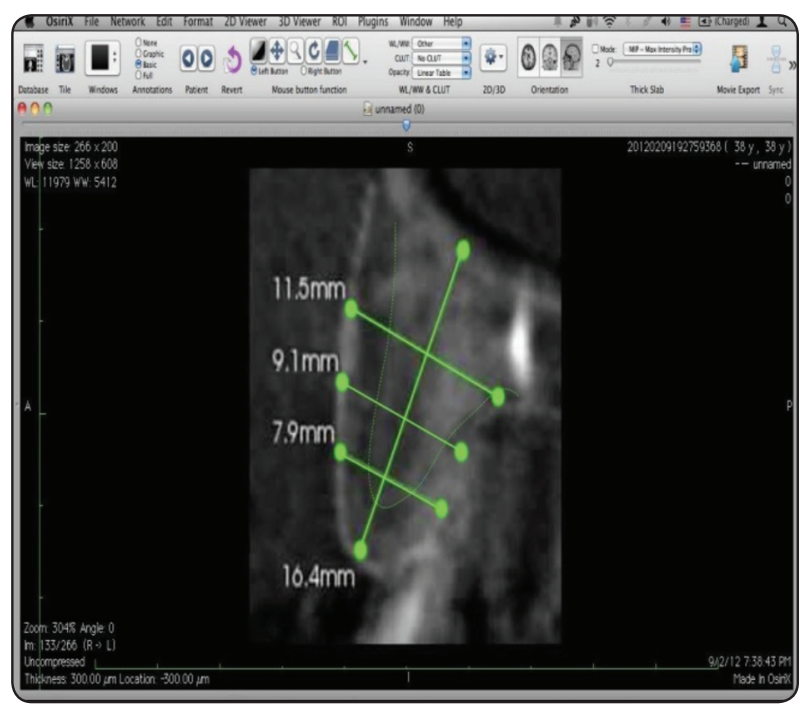

Fig.(7) Alveolar bone height and bone width measurements post-operative. 


\section{Densitometric analysis of the newly formed bone:}

\section{Bone density calculation}

Densitometric analysis of the grafted area 6 months post-operatively was performed and compared with native bone. Bone density was assessed in standardized sagittal cuts from both preoperative \& 6 months post-operative CBCT, using Osirix (V.5.9) software. Analysis of bone density was performed by taking 3 random readings using rectangular shapes with pre-specified area of 0.20 $\mathrm{cm} 2$ from each of native bone and newly formed bone, then an average mean values was calculated in Hounsfield units (HU).

\section{Statistically Analysis}

All data was collected and statistical analysis was performed to determine the statistical significance using IBM SPSS software package version 20.0."Qualitative data were described using number and percent. Quantitative data were described using Range (minimum and maximum), mean, standard deviation and median. The distributions of quantitative variables were tested for normality using Kolmogorov-Smirnov test, Shapiro-Wilk test and D'Agstino test, also Histogram and $Q Q$ plot were used for vision test. ${ }^{* *}$ If it reveals normal data distribution, parametric tests was applied. For normally distributed data, paired t-test is used to analyse two paired data. Significance of the obtained results was judged at the $5 \%$ level.

\section{RESULTS}

A total of 16 patients, 12 males $(75 \%)$ and 4 females $(25 \%)$ with anterior alveolar ridge defects were involved in this study. All patients were included for statistical analysis. Data was reported as mean \pm standard deviation.

\section{Clinical Results}

The study involved 12 males and 4 female patients with ages ranging from 22 to 51 years with a mean age of $38.62 \pm 9.12$ years.

No unexpected complications were observed. The immediate post-operative follow-up showed mild facial swelling, local edema and/or erythema were common and resolved within 1 week. No infection or necrosis of the flap was observed in any of the cases. Flap dehiscence and exposure of the titanium mesh was observed in two patients at 14 days and 4 months, respectively. These patients were advised to use the Chlorhexidine ${ }^{* * *}$ mouth wash and follow-up with irrigation twice a week until the exposed area started to granulate. Soft tissue healing was achieved at the center with exposed mesh edges at the margins. At the end of the follow-up period no signs of infection or evidence of bone resorption were found. Figure (8)

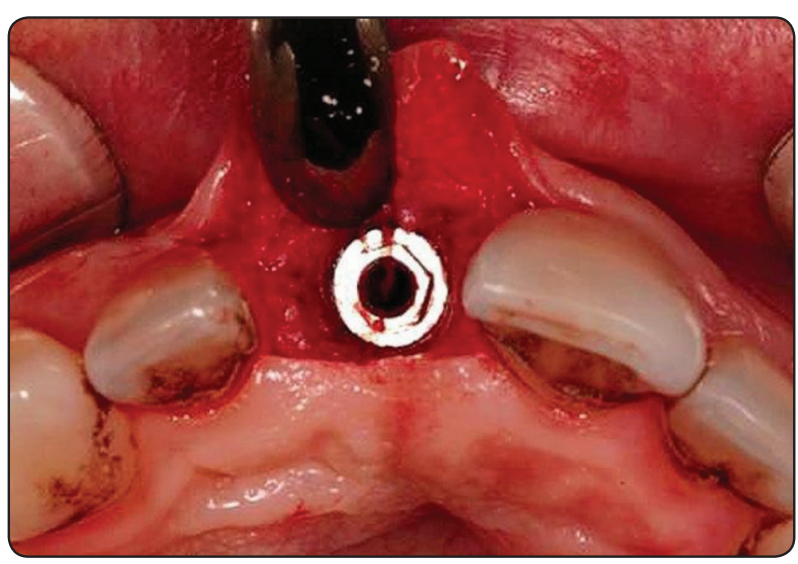

Fig.(8) Showing placed implant

\footnotetext{
* Kotz S, Balakrishnan N, Read CB, Vidakovic B. Encyclopedia of statistical sciences. 2nd ed. Hoboken, N.J.: Wiley-Interscience; 2006.

** Kirkpatrick LA, Feeney BC. A simple guide to IBM SPSS statistics for version 20.0. Student ed. Belmont, Calif.: Wadsworth, Cengage Learning; 2013.

*** Antiseptol: kahira pharm \&chemind co.
} 


\section{Radiographic Results}

At the end of the 6 months follow-up period all patients achieved bone formation. The postoperative CBCT scans showed newly formed bone and increase in alveolar bone dimensions in all cases. All augmented alveolar ridges showed good maturation of bone graft on the follow-up CBCT scans, with evidence of normal bony architecture consisting of a layer of cortical bone on labial and palatal surfaces and dense core of cancellous bone between the two cortices. No evidence of fibrosis or scarring was noted in the bone graft.

\section{Radiographic evaluation of alveolar ridge width measurements}

Pre-operatively the defective alveolar ridge width at $25 \%$ ranged from $0.18-0.37 \mathrm{~cm}$ with a mean of $0.29 \pm 0.06 \mathrm{~cm}$, while at $50 \%$ alveolar ridge width ranged from $0.41-0.64$ with a mean of $0.50 \pm$ 0.07 and at $75 \%$ alveolar ridge width ranged from $0.64-0.85$ with a mean of $0.72 \pm 0.07$.

Post-operatively the alveolar ridge width in Group I (rhBMP-2) at 25\% ranged from 0.54 $0.75 \mathrm{~cm}$ with a mean of $0.65 \pm 0.06$, while at $50 \%$ alveolar ridge width ranged from $0.63-0.87 \mathrm{~cm}$ with a mean of $0.73 \pm 0.09$ and at $75 \%$ alveolar ridge width ranged from $0.73-1.05$ with a mean of $0.86 \pm 0.10$. Paired sample t-test showed a significant increase of bone width six months post-operatively $(\mathrm{p}<0.001)$ Figures $(9,10)$

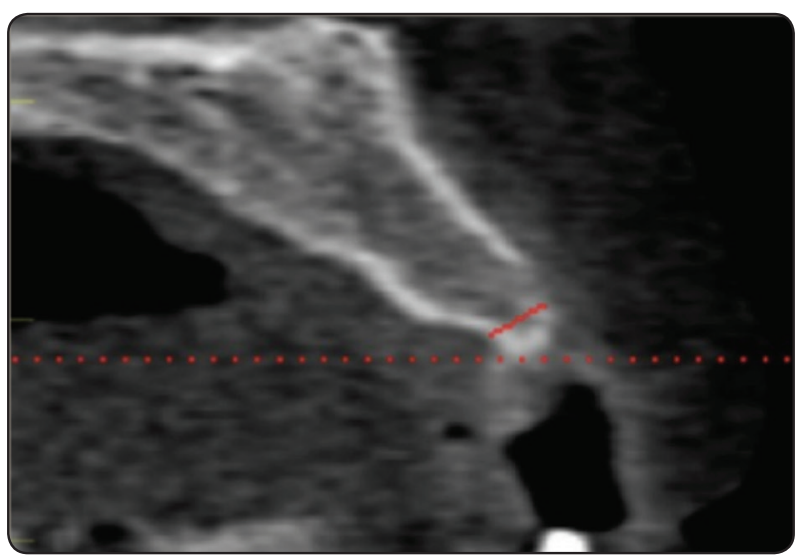

Fig. (9) Showing pre-operative CBCT.

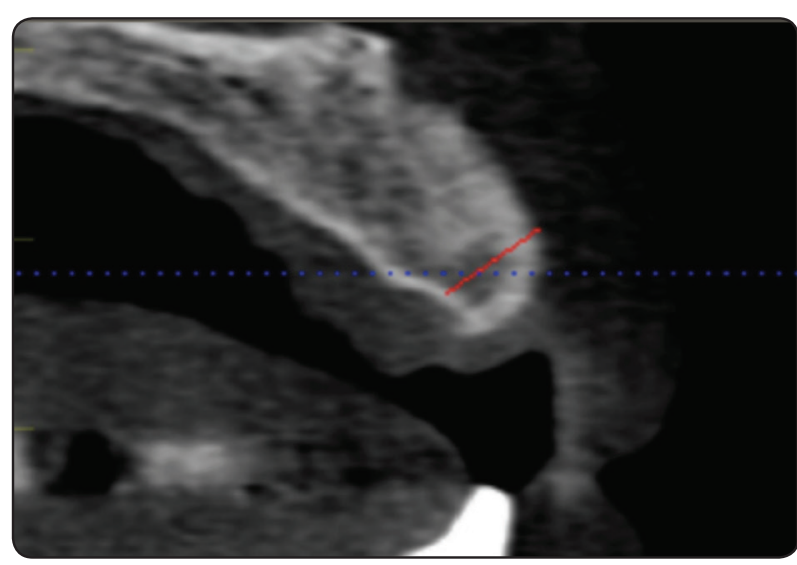

Fig.(10) Showing post-operative CBCT.

The alveolar ridge post-operative width in Group II (Autogenous bone) at $25 \%$ ranged from $0.57-0.79 \mathrm{~cm}$ with a mean of $0.68 \pm 0.08$, while at $50 \%$ alveolar ridge width ranged from $0.63-0.91$ $\mathrm{cm}$ with a mean of $0.77 \pm 0.07$ and at $75 \%$ alveolar ridge width ranged from $0.71-1.12$ with a mean of $0.91 \pm 0.10$. Sample T-test showed non-significant difference in alveolar ridge width between Group I and Group II 6 months postoperatively at 25\%, 50\% and $75 \%$ of the ridge (P>0.01). Table (1)

TABLE (1): Comparison between group I \& Group II pre and post-operative according to bone width $(\mathrm{n}=8)$

\begin{tabular}{|c|c|c|c|c|}
\hline \multirow{2}{*}{ Bone Width } & \multicolumn{2}{|c|}{$\begin{array}{c}\text { Group I } \\
\text { (rh-BMP-2) }\end{array}$} & \multicolumn{2}{c|}{$\begin{array}{c}\text { Group II } \\
\text { (Autogenous Bone) }\end{array}$} \\
\cline { 2 - 5 } & $\begin{array}{c}\text { Pre- } \\
\text { Operative }\end{array}$ & $\begin{array}{c}\text { Post- } \\
\text { Operative }\end{array}$ & $\begin{array}{c}\text { Pre- } \\
\text { Operative }\end{array}$ & $\begin{array}{c}\text { Post- } \\
\text { Operative }\end{array}$ \\
\hline $25 \%$ (cm) & & & & \\
\hline Min. - Max. & $0.18-0.37$ & $0.54-0.75$ & $0.16-0.41$ & $0.57-0.79$ \\
\hline Mean & 0.29 & 0.65 & 0.31 & 0.68 \\
\hline $50 \%$ (cm) & & & & \\
\hline Min. - Max. & $0.41-0.64$ & $0.63-0.87$ & $0.45-0.68$ & $0.63-0.91$ \\
\hline Mean & 0.50 & 0.70 & 0.54 & 0.77 \\
\hline $75 \%$ (cm) & & & & \\
\hline Min. - Max. & $0.64-0.85$ & $0.73-1.05$ & $0.68-0.92$ & $0.71-1.12$ \\
\hline Mean & 0.71 & 0.83 & 0.75 & 0.91 \\
\hline
\end{tabular}




\section{Radiographic evaluation of alveolar ridge height} measurements

The defective alveolar ridge pre-operative height ranged from 1.06-1.36 $\mathrm{m}$ with a mean of $1.19 \pm 0.09$ $\mathrm{m}$. The alveolar ridge post-operative height in Group I (rhBMP-2) ranged from 1.49-2.08 m with a mean of $1.78 \pm 0.21$. Paired sample t-test showed a significant increase of bone height six months post-operatively. $(\mathrm{p}<0.001)$. The alveolar ridge post-operative height in Group II (Autogenous bone) ranged from 1.58-2.12 $\mathrm{mm}$ with a mean of $1.85 \pm 0.28$. Sample T-test showed non significant difference in alveolar ridge height between Group I and Group II 6 months postoperatively. (P>0.01). Graph (1).

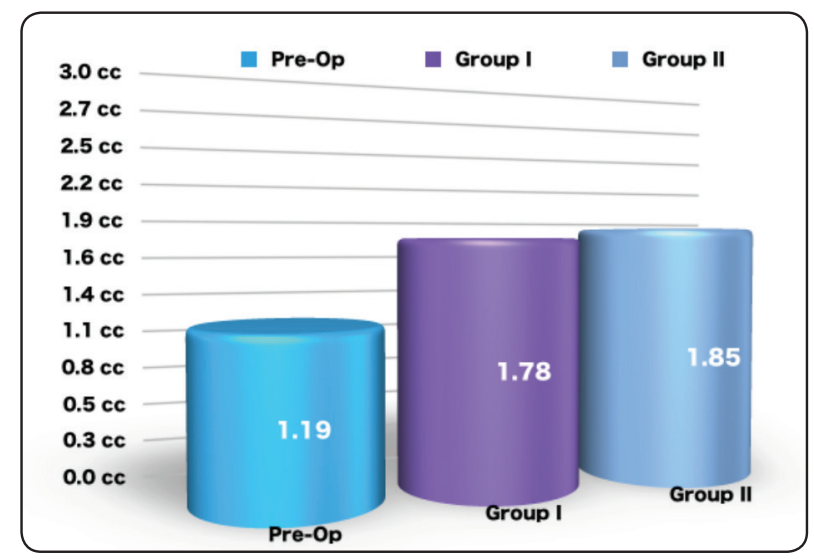

Graph 1 : Showing alveolar ridge pre-operative height (preop) and alveolar ridge post-operative height Group I \& Group II.

\section{Radiographic evaluation of alveolar ridge Vol- ume measurements}

The defective alveolar ridge pre-operative volume ranged from $1.16 \mathrm{cc}-1.61 \mathrm{cc}$ with mean volume of $1.37 \pm 0.16 \mathrm{cc}$. The alveolar ridge postoperative volume in group I (rhBMP-2) ranged from $1.92 \mathrm{cc}-2.77 \mathrm{cc}$ with mean volume of $2.53 \pm 0.27$.
Paired sample t-test showed a significant increase of bone volume six months post-operatively ( $p$ $<0.001)$. While the alveolar ridge post-operative volume in group II (Autogenous Bone) ranged from $1.97 \mathrm{cc}-2.82 \mathrm{cc}$ with mean volume of $2.53 \pm 0.27$. Sample T-test showed non significant difference in alveolar ridge volume between Group I and Group II 6 months postoperatively. (P>0.01).Graph (2)

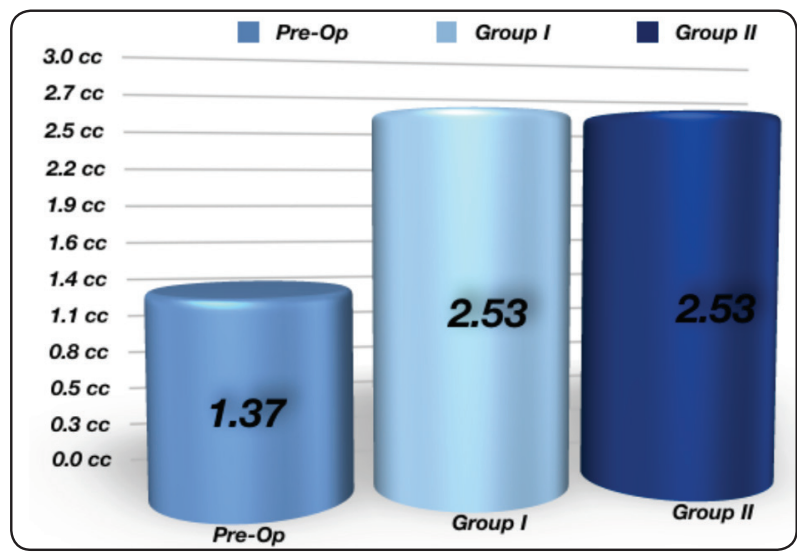

Graph 2: Showing alveolar ridge pre-operative volume (pre-op) and alveolar ridge post-operative volume in Groups I \& II

\section{Density measurements}

The density of native bone ranged between 545.0 and $776.90 \mathrm{HU}$ with a mean value of 668.75 $\pm 80.37 \mathrm{HU}$. The density of the newly formed bone in Group I (Recombinant BMP-2) six months postoperatively ranged between 436.04 and $650.30 \mathrm{HU}$ with a mean value of $561.89 \pm 66.94 \mathrm{HU}$.

While the density in Group II (Autogenous bone) ranged between 482.02 and $730.70 \mathrm{HU}$ with a mean value of $620.52 \pm 56.24 \mathrm{HU}$

Sample T-test showed non significant difference between Group I and Group II 6 months postoperatively. (P>0.01). Graph (3) 


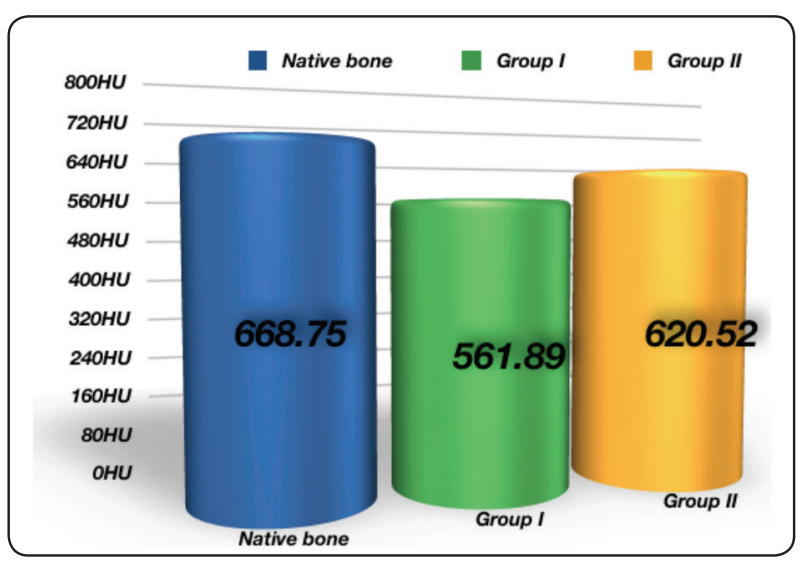

Graph 3 : Showing mean density of native bone versus mean density of the newly formed bone in Groups I \& II

\section{DISCUSSION}

The objective of this study was to evaluate the effect of rhBMP-2 / ACS on bone formation in anterior maxillary alveolar ridge defects and compare it with autogenous bone grafting. No unexpected post- operative outcomes were observed. rhBMP-2/ ACS yielded statistically significant radiographic horizontal and vertical bone gain at the immediate sub-, mid- and apical crestal levels comparable to autogenous bone grafting. A total of 16 implants were successfully installed postoperatively.

Sampath\&Reddi ${ }^{[3,37]}$ created a crude but highly reproducible bioassay for BMP for ectopic bone formation. The assay was based on the activity of the enzyme alkaline phosphatase enzyme and the content of calcium in the newly formed bone. Reddi ${ }^{[38,39]}$ proposed that BMPs are responsible for the initiation of a cascade of developmental events, in which progenitor cells in the bone marrow were induced by these factors to produce bone cells leading to bone regeneration. In a recent review Reddi ${ }^{[40]}$ proposed naming BMPs also as body morphogenetic proteins, due to their extensive roles in various tissues and organs beyond the bone .

In humans several members are under the designation of BMPs, from BMP-2 to BMP-18. BMP-1 is not a member of the BMP family. It is a misidentified protein with chordinase and pro-collagen proteinase activities, implicated in embryonic patterning ${ }^{[41]}$. The biological functions of BMPs are mainly related to bone and cartilage formation ${ }^{[42]}$, although BMP-8b, -10 and -15 do not have known roles in bone or cartilage. BMP10 is involved in cardiac development and BMP15 in ovarian physiology ${ }^{[43,44]}$. BMP-8b is involved in reproductive cells $\mathrm{s}^{[45]}$ are considered to be BMPs. BMP-12, -13 and - 14 are named cartilagederived morphogenetic proteins (CDMPs), as these induce chondrogenic phenotypes rather than osteogenesis ${ }^{[46]}$.

Early rh-BMP use in humans was reported in case report whereby reconstruction of a large mandibular resection defect was done following removal of an ameloblastoma ${ }^{[47]}$. In 2002, the Food and Drug Administration (FDA) approved rhBMP-2 for autograft replacement in spinal fusions, followed by approval of its use for open tibia fractures in 2004, and in 2007 for sinus augmentations, and localized alveolar ridge defects ${ }^{[48]}$.

Several clinical studies evaluated the utility of rhBMP-2 / ACS for craniofacial indications; conducted within the framework of FDA approval in 2007. These studies include randomized clinical trials where rhBMP-2 / ACS yielded clinically relevant bone formation for maxillary sinus augmentation ${ }^{[49,50]}$. Also, Fiorellini et al., ${ }^{[51]}$ supported alveolar bone preservation / augmentation at complex extraction sites. Other clinical studies and case series have demonstrated variable outcomes with the use of rhBMP-2/ACS ${ }^{[52,53,54]}$ or unfavorable outcomes when combined with a particulate bovine bone mineral bio-material as reported by Jung et al., in 2009 and Kao et al., in 2012. ${ }^{[55,56]}$

The rhBMP-2/ACS was used in the concentration of $1 \mathrm{mg} / \mathrm{cc}$, which has been proved to be optimal for bone augmentation ${ }^{[57]}$. Based on the comparison of several doses of rhBMP-2 / ACS (0.75 and 1.5 $\mathrm{mg} / \mathrm{cc}$ ) for treating post-extraction defects, a higher dose seems to affect the amount and velocity of the newly formed bone ${ }^{[58]}$. However, peri-implant bone 
resorption and seroma formation has been observed to be considerably more extensive and aggressive at a higher rhBMP-2 concentration ${ }^{[59]}$. The results reported by Carter et al. ${ }^{[60]}$ attributed some failures of bone regeneration using rhBMP-2 due to infection . Documented adverse events linked to rhBMP-2 include; bone resorption at the graft site, severe neck swelling, hematoma, painful seroma, ectopic bone formation and severe dysphagia [47,49,51,54,60]. The most frequent complication is edema, noted in our cases as well, which may occur partially due to fast releasing of of the full dose of rhBMP-2 from ACS once being placed in the defect.

Studies demonstrated that after 15 minutes of soaking, under normal surgical handling, $95 \%$ of the rhBMP2 is retained on the wet sponge. The manufacturer recommends use of the rhBMP2/ACS within 2 hours after the final product is prepared. A disadvantage of rhBMP-2/ACS is its half-time of approximately 7-16 minutes with a burst release within 1 hour of implantation and lack of any controlled releasing property ${ }^{[61]}$.

Furthermore, it should be noted that patients can develop antibodies to the collagen, which does not appear to have a clinical effect ${ }^{[62]}$. In the present study, no remnants of collagen carriers were seen after 6 months in the augmentation sites. The authors chose ACS because of previous studies showing excellent biocompatibility. Also because ACS is not osteoinductive, thus any bone formation would be contributed to the rhBMP-2, besides the fact that it does not only play a role in rhBMP-2 delivery, but also provides a cell anchorage for cell differentiation ${ }^{[63]}$.

Most of the authors found several problems when using rhBMP-2/ACS in human surgical procedures. Some disadvantages of the collagen carrier proved to be related to its lack of structural stability and inability to maintain space as it is compressed by soft-tissues overlying the defect ${ }^{[64,65]}$. For these reasons, current research attempts are directed towards developing a matrix with more structural ability capable of maintaining the space for bone induction during healing ${ }^{[60]}$. Hence, the treatment protocol in this study included the use of a titanium mesh as a mean of physical structure to create and maintain space for regeneration to occur.

The final outcome in this study was represented by gaining $17.8 \mathrm{~mm}$ of bone height in the anterior maxillary alveolar ridge, which was comparable with the results achieved by using the concentration of $1.5 \mathrm{mg} / \mathrm{cc}$ in a randomized, controlled, rhBMP2-dosing study for sinus floor augmentation study by Boyne et al., in 2005 where the results showed newly formed bone height of $7.83 \mathrm{~mm} .{ }^{[49]}$

In addition to bone width gain of $3.6 \mathrm{~mm}, 2.3$ $\mathrm{mm}$ and $1.4 \mathrm{~mm}$ at the immediate sub-, mid- and apical crestal levels respectively ${ }^{[60]}$ which was also comparable with the results achieved by using the concentration of $1.5 \mathrm{mg} / \mathrm{cc}$ in a clinical trial by Fiorellini et al., in 2005 including 80 subjects evaluating the application of rhBMP-2/ACS for alveolar bone preservation/augmentation at complex extraction sites to assess horizontal bone gain following a 4-month healing interval using a radiographic methodology somewhat similar to that in this study. The results showed a mean radiographic gain in alveolar width of $3.3 \mathrm{~mm}, 2.9$ and $2.6 \mathrm{~mm}$ at the sub- and mid- and crestal levels respectively. ${ }^{[51]}$ A study by De Freitas et al.$^{[67]}$ in 2013 , to assess horizontal bone gain in anterior maxilla used a methodology somewhat similar to that in this study except using rhBMP-2 at a higher concentration of $1.5 \mathrm{mg} / \mathrm{cc}$. The study yielded bone width gain of 3.5 $\mathrm{mm}, 2.5 \mathrm{~mm}$, and $3.7 \mathrm{~mm}$ at the immediate sub-, mid- and apical crestal levels respectively which was also comparable with the results in this study.

Nevertheless, Howell et al., ${ }^{[53]} 1997$ and Cochran et al., ${ }^{[54]} 2000$ showed in a case series counting six subjects an average clinical and radiographic horizontal bone gain comprising 0.4 and $0.2 \mathrm{~mm}$, respectively, following application of rhBMP-2/ ACS in the edentulous anterior maxilla. These findings contrast the results in this study in which 
Space-provision offered by the titanium mesh, may explain the favorable outcomes.

Radiographic findings in our study revealed that the density of newly formed bone was comparable to the native bone. The mean bone density of newly formed bone was $561.89 \mathrm{HU}$ whilst that of the native bone was $668.75 \mathrm{HU}$. These results contribute to previous findings that rhBMP-2 induced bone continues maturing and by $12-24$ weeks post implantation cannot be radiographically differentiated from the resident bone. ${ }^{[68]}$ Radiolucent voids in rhBMP-2 induced bone have been observed in multiple studies utilizing a variety of carriers in supra-alveolar or saddletype defects in dogs, being detected as seromas or sterile accumulations of serum in a circumscribed location ${ }^{[68,69]}$. However, no voids were detected in our study, which is in accordance with findings from other human reports following the use of rhBMP-2 ${ }^{[55]}$. Several groups of authors showed that in animal models rhBMP-2 induced formed bone accommodates not only installation and osseointegration, but also long- term functional loading of endosseous dental implants. ${ }^{[65,69-73]}$

In perspective, it is necessary to acknowledge the impact that defect characteristics likely contribute to the outcomes. Whereas extraction sites represent contained space-providing (inlay) defects; horizontal onlay non-naturally spaceproviding defects as in the anterior atrophic maxilla present additional challenge. Obviously technical challenges adapting the titanium mesh to the site and soft tissue limitations restricting space-provision dictate the overall outcomes in onlay settings such as in this study.

In previous pre-clinical studies demonstrating tissue engineering principles, rhBMP-2/ACS was combined with a space-providing macro-porous expanding Polytetrafluoroethylene (ePTFE) membrane or titanium mesh as in this study using an onlay model ${ }^{[70,74]}$. The porous membrane or titanium mesh not only provides a space for bone formation but also directs the geometry of the newly formed bone. Adopting these principles in this study, rhBMP-2/ ACS induced newly formed bone was achieved using an open porous structure titanium mesh providing space and wound stability reducing apparent trauma or compression of the wound during the critical early stages of wound healing and bone formation. Protection of the wound became specially complicated due to the need to balance the patients' desire for aesthetics and function given the location of the wound site and corresponding swelling. Nevertheless, wound closure for primary intention healing was achieved by advancing the flaps through fenestration of the periosteum and the careful use of suturing techniques.

Techniques to measure bone volume in the jaws have not been well-described. The aim of the present study was to use CBCT scans typically used in implant planning for volumetric assessment of the defect and to measure the amount of bone formed in the grafted area at the end of follow-up period. As we wished to measure the change in size of alveolar defects pre- and postoperative, ideally we would likely measure the size of the defects themselves. However, the lack of one or more borders created certain difficulties. One way of dealing with the missing crestal cortex is to define the defect by simply connecting the buccal and palatal crestal cortices, but this can make the interpretation of the data extremely difficult and of little or no use.

However, we overcame the difficulty to define the defect directly by ignoring its dimensions and measuring the absolute amount of bone change in a region of interest (ROI). The same region was selected on both the pre- and postoperative CT scans, making it possible to measure the absolute change in bone volume following treatment while still meeting our primary objective, determining the efficacy of rhBMP-2.

In our study rhBMP-2/ACS appears to be a reliable treatment option for defective alveolar ridge augmentation of the anterior maxilla provided that 
conditions for optimal wound healing including space-provision, wound stability and primary intention healing are met. This allows dental implants placement in defective anterior maxillary ridges which otherwise would not be eligible for implantbased rehabilitation. However, further research is indicated to better understand and determine optimal dose of rhBMP-2, timing of its release and carrier scaffold to yield predictable and reliable bone regeneration. In this study we used the absorbable collagen sponge carrier due to its binding properties and sustained release of rhBMP-2, but this carrier was not tough enough to withstand tension of the flap, thus required the use of a titanium mesh as a mean of physical structure to create and maintain space for adequate bone formation. Therefore, another carrier is needed to withstand this tension and provide the space required for adequate bone formation. Bone Density assessment by CBCT is not as accurate as CT scan, but it is better than grey scale used before.

In conclusion, rhBMP-2/ACS is an alternative source to substitute the autogenous bone graft to obtain newly formed bone and eliminate the dilemma and morbidity related to donor site.

\section{REFERENCES}

1. Atwood DA. Reduction of residual ridges: A major oral disease entity. J Prosthet Dent; 26: 266-279.1971

2. Cawood JI, Howell RA. A classification of the edentulous jaws. Int J Oral MaxillofacSurg; 17:232-236. 1998

3. Van der Weijden F, Dell'Acqua F, Slot DE. Alveolar bone dimensional changes of post-extraction sockets in humans :a systematic review. J ClinPeriodontol; 36 :1048-1058. doi: 10.1111/j.1600-051X.2009.01482.x.2009

4. Aimetti M, Romano F, Griga FB, Godio L. Clinical and histologic healing of human extraction sockets filled with calcium sulfate. IntJ.OralMaxillofac Impl;24:902-9. 2009

5. Lekovic V, Kenney EB, Weinlaender M, Han T, Klokkevold $\mathrm{P}$, Nedic M. et al. A bone regenerative approach to alveolar ridge maintenance following tooth extraction. Report of 10 cases. J Periodontol;68:563-70. 1997

6. Schropp L, Wenzel A, Kostopoulos L, Karring T. Bone healing and soft tissue contour changes following single- tooth extraction: a clinical and radiographic 12-month prospective study. Int J Period Restor Dent;23: 313-23. 2003

7. Att, W., Bernhart, J. \&Strub, J.R.Fixed rehabilitation of the edentulous maxilla: possibilities and clinical outcome. Journal of Oral and Maxillofacial Surgery, Vol.67, No.11 (Suppl), (November 2009), pp. 60-73, ISSN 0278-2391. 2009

8. Araújo MG, Lindhe J. Dimensional ridge alterations following tooth extraction. An experimental study in the dog. J Clin Periodontol;32:212-8. 2005

9. Ashman A, Rosenlicht J. Ridge preservation: Addressing a major problem in dentistry. Dent Today; 12:80-84.121 1993

10. Ashman A. Postextraction ridge preservation using synthetic alloplast. Implant Dent; 9:168-176.2000

11. Jahangin L, Devlin 1 1, Ting K et al. Current perspectives in residual ridge remodeling and its clinical implications: a review. J Prosthet Dent. 80: 224-37, 1998

12. Pietrokovski J, Massler M. Alveolar ridge resorption after tooth extraction. J Prosth Dent; 17:21-7.1967

13. Johnson K. A study of the dimensional changes occurring in the maxilla following tooth extraction. Austr Dent J; 14:241-4. 1969

14. MacKay HF, Shykoff JC, Sàndor GKB. Diphenylhydantoin and the height of the residual dental alveolar ridge. Proceedings of the Second International Prosthodontic Congress, St. Louis: C.V. Mosby Company; 344-345.1979

15. Iasella, J.M., Greenwell, H., Miller, R.L., Hill, M., Drisko, C., Bohra, A.A. \& Scheetz, J.P. Ridge preservation with freeze-dried bone allograft and a collagen membrane compared to extraction alone for implant site development: a clinical and histologic study in humans. Journal of Periodontology 74: 990-999. 2003

16. Callan DP1, Salkeld SL, Scarborough N.Histologic analysis of implant sites after grafting with demineralized bone matrix putty and sheets.Implant Dent.;9(1):36-44. 2000

17. Desai BM: Osteobiologics. Am J Orthop;36:8-11. 2007

18. A. Alex Jahangir, MD; Ryan M. Nunley, MD; Samir Mehta, MD; AlokSharan, MD; and the Washington Health Policy Fellows.Bone-graft substitutes in orthopaedicsurgery. AAOS Now Issue.Volume 8, Number 4.January 2008

19. SmithJD, Abrahamson M. Membraneous vs. endochondral bone autografts.Arch Otoloryngol;99:203^5.1974

20. Zins JE, Whitaker LA. Membranous versus endochondral bone: implications for craniofacial reconstruction. PlastReconstr Surg; $72: 778^{\wedge} 85.1983$

21. Jensen J, Sindet-Pedersen S. Autogenousmandibula bone grafts and osseointegrated implants for reconstrcution of 
severely resorbed maxilla: a preliminary report. J Oral Maxillofac Surg;49:1277^87.1991

22. Marx RE, Shellenberger T, Wimsatt J, Correa P. Severely resorbed mandible: Predictable reconstruction with soft tissue matrix expansion (tent pole) grafts. J Oral MaxillofacSurg; 60: 878-888. 2002

23. Buchardt H. The biology of bone graft repair. Clinical Orthop; 174:28-42.1983

24. Atwood DA. Postextraction changes in the adult mandible as illustrated by microradiographs of midsagittal sections and serial cephalometric roentgenograms. J Prosthet Dent 1963;13: 810-24.

25. Neuhof H. SurgGynecObst 1917;24:383.

26. Huggins C. Arch Surg 1931;22:377.

27. Levander G: On the formation of new bone in bone transplantation. ActaChirScand 74:425 426, 1934.

28. Levander G: A study of bone regeneration. SurgGynecolObstet 67:705 714,1938.

29. Sharrard WJ, Collins DH: The fate of human decalcified bone grafts. Proc Roy Soc Med 54:1101 1102, 1961.

30. Ray RD, Holloway JA: Bone implants. Preliminary report of an experimental study. J Bone Joint Surg Am 39:1119 1128, 1957.

31. Urist, M. R. Bone: formation by autoinduction, Science 150, 893-899,1965

32. Urist, M. R., and Strates, B. S. Bone morphogenetic protein, J Dent Res 50, 1392-1406.,1971

33. SampathTK ,ReddiAH.Dissociative extraction and reconstitution of extracellular matrix components involved in local bone differentiation. ProcNatlAcadSci USA;78:7599- 7603. 1981

34. Wozney JM, Rosen V, Celeste AJ, et al.; Novel regulators of bone formation: molecular clones and activities. Science 242:1528 - 1534.1988

35. Nakashima M,ReddiAH;Theapplication of bone morphogenetic proteins to dental tissue engineering. Nat Biotechnol 21: 1025-1032.2003

36. Seeherman H, Wozney JM.; Delivery of bone morphogenetic proteins for orthopedic tissue regeneration. Cytokine Growth Factor Rev 16: 329-345.2005

37. Reddi, A. H. BMPs: Actions in flesh and bone. Nature Medicine, 3(8), 837-839. DOI: 10.1038/nm0897-837,1997

38. Reddi AH, Huggins C.; Biochemical sequences in the transformation of normal fibroblasts in adolescent rats. ProcNatlAcadSci USA 69: 1601-1605.1972

39. Reddi AH.; Cell biology and biochemistry of endochondral bone development. CollRelat Res 1: 209-226. 1981
40. Reddi AH.; BMPs: from bone morphogenetic proteins to body morphogenetic proteins. Cytokine Growth Factor Rev 16: 249-250.2005

41. Kessler E, Takahara K, BiniaminovL, et al.; Bone morphogenetic protein-1: the type I procollagen C-proteinase. Science 271: 360-362.1996

42. Ebendal $\mathrm{T}$, Bengtsson $\mathrm{H}$, Soderstrom S. Bone morphogenetic proteins and their receptors: potential functions in the brain. J Neurosci Res;51:139-146.1998

43. Chen H,Shi S, Acosta L, et al;BMP10 is essential for maintaining cardiac growth during murine cardiogenesis. Development 131: 2219-2231.2004

44. Knight PG, Glister C.; TGF $\beta$ superfamily members and ovarian follicle development. Reproduction 132: 191206.2006

45. Zhao GQ, Deng K, Labosky PA, et al.; The gene encoding bone morphogenetic protein $8 \mathrm{~B}$ is required for the initiation and maintenance of spermatogenesis in the mouse. Genes Dev 10: 1657 - 1669.1996

46. Reddi AH.; Cartilage morphogenetic proteins: role in joint development, homoeostasis, and regeneration. Ann Rheum Dis 62(suppl 2): ii73-78.2003

47. Moghadam HG, Urist T, Sandor GK, et al: Suc- cessful mandibular reconstruction using a BMP bio-implant. J CraniofacSurg 12:119, 2001.

48. Carter TG, Brar PS, Tolas A, et al: Off-label use of recombinant human bone morphogenic protein-2 (rhBMP-2) for reconstruction of mandibular bone defects in humans. J Oral MaxillofacSurg 66:1417, 2008.

49. Boyne PJ, Lilly LC, Marx RE, et al: De novo bone induction by recombinant human bone morphogenic protein-2 (rhBMP-2) in maxillary sinus floor augmentation. J Oral MaxillofacSurg 63:1693, 2005.

50. Triplett, R. G., Nevins, M., Marx, R. E., Spagn- oli, D. B., Oates, T. W., Moy, P. K. \& Boyne, P. J. (2009) Pivotal, randomized, parallel evalu- ation of recombinant human bone morphogenetic protein-2/absorbable collagen sponge and autogenous bone graft for maxillary sinus floor augmentation. Journal of Oral and Maxillofa- cial Surgery 67, 1947-1960.

51. Fiorellini, J. P., Howell, T. H., Cochran, D., Malmquist, J., Lilly, L. C., Spagnoli, D., Tolj- anic, J., Jones, A. \& Nevins, M. Ran- domized study evaluating recombinant human bone morphogenetic protein-2 for extraction socket augmentation. Journal of Periodontology 76, 605613.2005 
52. Boyne PJ, Marx RE, Nevins M, et al. A feasibility study evaluating rhBMP-2/ absorbable collagen sponge for maxillary sinus floor augmentation. Int $\mathrm{J}$ Periodontics Restorative Dent; 17:11-25.1997

53. Howell, T. Howard; Fiorellini, Joseph; Jones, Archie; Alder, Marden; Nummikoski, Pirkka; Lazaro, Manuel; Lilly, Leslie; Cochran, David.A Feasibility Study Evaluating rhBMP-2/Absorbable Collagen Sponge Device for Local Alveolar Ridge Preservation or Augmentation. International Journal of Periodontics \& Restorative Dentistry;Apr, Vol. 17 Issue 2, p124.1997

54. Cochran, D. L., Jones, A. A., Lilly, L. C., Fiorel- lini, J. P. \& Howell, H. Evaluation of recombinant human bone morphogenetic pro- tein-2 in oral applications including the use of endosseous implants: 3-year results of a pilot study in humans. Journal of Periodontology 71, 1241-1257.2000

55. Jung, R. E., Windisch, S. I., Eggenschwiler, A. M., Thoma, D. S., Weber, F. E. \&Hammerle, C. H. A randomizedcontrolled clinical trial evaluating clinical and radiological out- comes after 3 and 5 years of dental implants placed in bone regenerated by means of GBR techniques with or without the addition of BMP-2. Clinical Oral Implants Research 20,660-666.2009

56. Kao, D. W., Kubota, A., Nevins, M. \&Fiorellini, J. P. The negative effect of combining rhBMP-2 and Bio-Oss on bone formation for maxillary sinus augmentation. International Journal of Periodontics and Restorative Dentistry 32, 61-67.2012

57. MckayWf, Peckham SM, Badura JM. A, Orthop, $31,729$. DOI: $10.1007 /$ s00264-007-0418-6.2007

58. deWijs FLJA, Cune MS. Immediate labial contour restoration for improved aesthetics: A radiographic study on bone splitting in anterior single-tooth replacement. Int J Oral MaxillofacImpl; 12:686-696.1997

59. Fiorellini, J. P., Howell, T. H., Cochran, D., Malmquist, J., Lilly, L.C., Spagnoli, D., Tolj- anic, J., Jones, A. \& Nevins, M. Ran- domized study evaluating recombinant human bone morphogenetic protein-2 for extraction socket augmentation. Journal of Periodontology 76, 605-613.2005

60. CarterTG,BrarPS,TO-LasA,Beirne OR,JOral MaxilSurg, 66, 1417. DOI: 10.1016/j. joms.2008.01.058.2008

61. Carter TG, Brar PS, Tolas A, et al: Off-label use of recombinant human bone morphogenic protein-2 (rhBMP-2) for reconstruction of mandibular bon defects in humans. J Oral MaxillofacSurg 66:1417, 2008.

62. D. Katanec et al.: Use of rhBMP2 in Alveolar Ridge Augmentation, Coll. Antropol.38. 1: 325-330.2014
63. Herford AS1, Boyne PJ, Williams RP.Clinical applications of rhBMP-2 in maxillofacial surgery. J Calif Dent Assoc.;35(5):335-41. May 2007

64. Murata M1, Huang BZ, Shibata T, Imai S, Nagai N, Arisue $\mathrm{M}$. Bone augmentation by recombinant human BMP-2 and collagen on adult rat parietal bone. Int J Oral Maxillofac Surg.;28(3):232-7. Jun 1999

65. Lek- NesKn, Yang J, Qahash M, Polimeni G, Susin C, Wikesjo Ume, Cli Oral Implants Res, 19 (2008) 1027. DOI: 10.1111/j.1600-0501..01567.x.2008

66. Jovanic SA, Hunt DR, Bernard GW, Spickermann H, Spiekermann H, Wozney JM, Wikesjo JM, Clin Oral Implants Res, 18.224. DOI: 10.1111/j.1600-0501.2006. 01324.x. 2007

67. De Freitas RM, Susin C, Spin-Neto R, Marcantonio C, Wikesjö UME, Pereira LAVD, Marcantonio E Jr. Horizontal ridge augmentation of the atrophic anterior maxilla using rhBMP-2/ACS or autogenous bone grafts: a proof-of- concept randomized clinical trial. J ClinPeriodontol; 40: 968-976.2013

68. Hunt DR, Jovanic SA, Wikesjo UM, Wozney JM, Bernard GW, J Periodontol, 72 (2001) 651. DOI: 10.1902/jop.72. 5.651 .2001

69. Schwarz F, Ferrari D, Sager M, Herten M, Hartig B, Becker J, Clin Oral Implants Res, 20 (2009) 1219. DOI: 10.1111/j.1600-0501.01796.x.2009

70. Wikesjo UM, Xiropaidis AV, Thomson RC, Cook AD, Selvig KA, Hardwick WR, J ClinPeriodontol, 30 (2003) 715. DOI: 10.1034/j.1600-051X.00364.x.2003

71. Jovanic SA, Hunt DR, Bernard GW, Spiekermann H, Nishmura R, Wozney JM, Wikesjo UM, Clin Oral Implants Res, 14, 793. DOI: 10.1046/j.0905-7161.2003. clr140617.x.2003

72. Jovanic SA, Hunt DR, Bernard GW, Spiekermann H, Wozney JM, Wikesjo UM, Clin Oral Implants Res, 18 (2007) 224. DOI: 10.1111/j.1600-0501.01324.x.2006

73. Lee, J., Lee, E. N., Yoon, J., Chung, S.-M., Prasad, H., Susin, C. \&Wikesjo E, U. M. E. Comparative study of Chinese Hamster Ovary cell- versus Escherichia coliderived bone morphogenetic protein- 2 using the criticalsize supraalveolarperi-implant defect model. Journal of Periodontology 84, 415-422. 2013

74. Wikesjo UM, Qahash M, Thomson RC, Cook AD, Rohrer MD, Wozney JM, Hardwick WR, Clin Oral Implants Res, 15. 194. DOI: 10.1111/j. 1600-0501. 2004.00971.x.2004 